\title{
Predictors of Reading Fluency in Second and Third Grade Students: Results from Bosnia and Herzegovina
}

\author{
Haris Memisevic, Daniel Malec \\ University of Sarajevo, Faculty of Educational \\ Sciences, Sarajevo, Bosnia and Herzegovina
}

\author{
Inga Biscevic \\ Herzegovina University, Department of Special \\ Education, Mostar, Bosnia and Herzegovina
}

\author{
Arnela Pasalic \\ Center Vladimir Nazor, Sarajevo, \\ Bosnia and Herzegovina
}

\begin{abstract}
Learning to read is one of the most important academic accomplishments in the early grades of elementary school. Knowing what factors contribute to reading ability would improve instructional practices. The goal of the present study was to examine the effects of semantic fluency, phonological fluency, rapid naming, inhibitory control, selective attention, and visual motor integration on reading fluency in 140 second and third grade students. The results of this study indicated that significant predictors of reading fluency were: selective attention, semantic fluency, inhibitory control, and rapid naming. However, the association between predictor variables and reading fluency was moderated by the students' grade. The article concludes with some suggestions on how to improve reading fluency in elementary school children, given that all predictors are susceptible to instruction.
\end{abstract}

Key words: reading fluency, elementary school children, academic achievement

\section{Introduction}

Reading ability is one of the most important academic skills, next to writing and basic math-

\footnotetext{
Acknowledgement

This study was partly supported by the Sarajevo Canton Ministry of Education under the Project "Executive functions in early primary school children". The funders had no role in study design, data collection and analysis, decision to publish, or preparation of the manuscript. We would like to thank all children, parents, and teachers who participated in this study.

Correspondence concerning this article should be addressed to Dr. Haris Memisevic, University of Sarajevo, Faculty of Educational Sciences, 71000 Sarajevo, Bosnia and Herzegovina. E-mail: hmemisevic@gmail.com
}

Received March 12, 2019 ematical skills. The preschool period and the early grades of elementaryschool are particularlyimportant for developing reading skills. One of the main goals of elementary school education is teaching children toread (Guo, Sun, Breit-Smith, Morrison, \& Connor, 2015). Earlyreading abilities are strong predictors of reading comprehension and general knowledge at later age (Cunningham \& Stanovich, 1997) and they represent the foundation of children'slater academic success (Lonigan, Burgess, \& Anthony, 2000).

Reading is a complex process consisting of reading fluency and linguistic comprehension (Hoover \& Gough, 1990) and these two constructs are moderately correlated with each other (Levy, 2001). Each of these processes is complex in its own right. This is best illustrated by the fact that neuro-anatomy of reading encompasses neural systems that support every aspect of language, visual and orthographic 
processes, working memory, attention, motor movements, and higher level comprehension and cognition (Norton \& Wolf, 2012).

Reading fluency has become a topic of major importance in the field of reading and the number of studies investigating it has increased in comparison to all other reading topics (Landerl \& Wimmer, 2008; Teale, Whittingham, \& Hoffman, 2018). Fluency definitions comprise the following skills in oral reading: 1) accuracy for reading words, 2) appropriate pace for reading text, and 3) prosody or expression (Antonacci, O'Callaghan, \& Berkowitz, 2014). Often viewed as a bridge between word identification and comprehension, fluency needs to be considered in any reading process framework, used to assess and intervene in case of children with reading difficulties (Bashir \& Hook, 2009). Reading fluency is a very good indicator of early reading development and overall reading competence (Cohen-Mimran, 2009; Fuchs et al., 2001; Hasbrouck \& Tindal, 2006; Morris \& Perney, 2018).

Skills leading to successful reading are developed in preschool period and these skills become coordinated into fluent reading in grades 1-5 (Paris, 2005). Many factors and skills may contribute to reading fluency, such as accuracy in recognition of visual stimuli and efficiency in identifying single sight words (Torgesen \& Hudson, 2006). Other factors related to reading development are phonological awareness and naming speed (David et al., 2007; Kirby, Parrila, \& Pfeifer, 2003). To date, a plethora of research has demonstrated the effects of phonological awareness on reading development (Carrillo, 1994; Chiappe \& Siegel, 1999; Lonigan et al., 2000; Stahl \& Murray, 1994). However, although very important, phonological awareness is not a sufficient condition for early reading (Bus \& Van Ijzendoorn, 1999). Another set of predictors, examined in relation to reading skills, are the executive functions skills. Executive functions are related to read- ing development, as they govern the integration of visual and linguistic information, as well as retrieval of linguistic information from the memory while learning to read (Altemeier, Abbott, \& Berninger, 2008). Executive functions are related to reading achievement (Monette, Bigras, \& Guay, 2011) and studies have shown that children with reading difficulties have also deficits in executive functions (Reiter, Tucha, $\&$ Lange, 2005). Several executive functions have been implicated to play a role in reading development, including working memory (Chiappe, Hasher, \& Siegel, 2000), inhibitory control (Allan et al., 2014), and cognitive flexibility (Cole, Duncan, \& Blaye, 2014).

Besides cognitive factors contributing to reading literacy, there are many personality factors such as motivation and self-confidence, which are related to reading skills (Netten, Droop, \& Verhoeven, 2011). Demographic factors such as gender have also been studied in relation to reading but the results seem to be inconclusive. Most of the conducted studies point to females' advantage in the language domain (Clinton et al., 2014; Voyer \& Voyer, 2014). However, there are also reports of no gender effects on reading measures between boys and girls (Berninger et al., 2008).

Reading is a foundation stone of learning and fundamental educational goal across the world (Wagner, 2017). Many children at early primary grades have problems in acquiring adequate reading skills. A report by US Department of Education indicated that $36 \%$ of fourth grade children were reading below the basic level (Katzir et al., 2006). Identification of children at risk of reading problems is particularly important, as research indicates that poor readers at an early age tend to be poor readers in later grades as well (Francis, Shaywitz, Stuebing, Shaywitz, \& Fletcher, 1996). Given its importance, it comes as no surprise that so much scientific attention has been given to improving reading. Still, many school-aged children 
struggle with reading and there are several distinct types of reading difficulties. Some of these difficulties are related to naming speed and phonological processes (Wolf \& Katzir-Cohen, 2001), and some are related to other factors such as visual attention.

Knowing which factors contribute to efficient reading might help educators in identifying and creating intervention programs even before children are formally taught to read. In addition to this, knowledge about the predictors of reading can inform practitioners and help them improve their professional practices. The goal of the present study is to examine the extent to which certain factors (verbal fluency, selective attention, inhibitory control, rapid naming, and visual-motor integration) are related to reading fluency in a sample of second and third grade students whose native language is Bosnian, and to examine whether there are differences in reading fluency in relation to children's gender.

\section{This Study}

Schoolchildren in Bosnia and Herzegovina start their formal education at the age of 6 years by enrolling into the first grade of elementary school, which is compulsory. Prior to enrolling in elementary schools, all children are required to attend obligatory preschool preparation program at the age of 5 years (one year prior to their enrollment in elementary school). However, in that preparation program children are not required to learn any academic content such as numbers and/or letters. As for the reading outcomes, children are expected to learn to read in the second grade of elementary school. The curriculum goals for the first grade of elementary school are related to learning letters, reading short words and learning to write. Thus, we did not assess first grade students on the task of reading fluency, although some children learn to read in the first grade. The sample for this study consisted of children in second and third grades, as these children are expected to know how to read. The first objective in this study was to examine whether there are differences between girls and boys in reading fluency, as the research in this domain is inconclusive. The second objective was to examine the predictors of reading fluency at early school age and their relative effect on reading fluency. Some predictors of reading fluency, such as phonologic awareness, have already been established in the literature for both, languages with transparent orthography (Öney \& Durgunoğlu, 1997) and languages with less transparent orthography (Anthony \& Francis, 2005). It is important to note that, at least in the Anglo-Saxon linguistic field, there are children who do not respond well to phonological-based treatments in learning to read (Wolf \& Katzir-Cohen, 2001). Also, in an orthographically regular language, such as Finnish, there seems to be a minor link between early phonological skills and reading fluency in second grade students (Puolakanaho et al., 2008) and thus, there is a need to find additional avenues of treatment of reading difficulties besides phonological skills. As for the predictors in this study, we examined the effects of verbal fluency, rapid object naming, inhibitory control, selective attention and visualmotor skills on reading fluency. The reasons for selecting these predictors are two-fold. First, they are theoretically founded in earlier studies (Norton \& Wolf, 2012), where the authors implied wider neural networks involved in reading fluency. However, the joint/confounding effect of these variables on reading fluency remains unclear. These predictors, apart from rapid naming, have not received much attention in scientific literature. Thus we wanted to enhance our understanding of how these predictors affect the reading skills. The second reason we were interested in these particular predictors is that they might be receptive to academic interventions both at school age and, more importantly, at preschool age. If proven significant, 
these predictors can systematically be targeted by preschool educators, which in turn would result in better reading fluency at school age and better academic outcomes. This is the first study examining predictors of reading fluency in early grade students, whose native language is Bosnian. This study is innovative in the way that it examines the relationship between some components of executive functions and reading fluency: 1) in transparent orthography (as most of the studies were conducted in English language), 2) in normative population of students (most of the studies were examining this link in students with reading/learning disabilities), and 3) the outcome measure in this study is reading fluency (most existing studies examined the link between executive functions and reading comprehension).

The specific research questions in this study are:

1) Are there gender differences in reading fluency in children attending second and third grade of elementary school?

2) What are the best predictors of reading fluency?

3) Does the strength of the association between predictors and reading fluency vary in relation to the children's grade?

\section{Method}

\section{Participants}

The sample for this study was convenient and it consisted of 140 (73 boys, 67 girls) children attending second and third grade of two elementary schools in the Sarajevo city. There were 70 students attending second grade (36 boys, 34 girls; mean age $=92.1$ months, $S D=3.6$ months) and 70 (37 boys, 33 girls; mean age = 103.1 months, $S D=5.6$ months) students attending third grade. According to the teachers' reports, children were free of any developmental disability or other neurological condition.

\section{Measures}

\section{Outcome Measure}

\section{Reading Fluency}

The outcome measure in this study was a test of reading ability. The students were required to read a text and the number of words read in one minute served as an outcome measure. We created the reading text for the purpose of this study and it was the same for both second and third grade students. The reading text was developed with consultation with children's teachers as to reflect the language curriculum. The methodology, originally developed by Deno (1985), involves students reading short passages of text to assess their reading fluency. This way of assessing reading fluency has many advantages, it is simple to perform, can differentiate between students of different reading ability and can easily serve as a measure of intervention efficacy (Fuchs et al., 2001).

\section{Predictors}

In this study we used the following predictors for reading fluency: 1) Verbal fluency measured through Semantic fluency and Phonological fluency task; 2) Rapid object naming test; 3) Inhibitory control test; 4) Selective attention test; and 5) Visual-motor integration skills. Although verbal fluency tests and rapid naming test are frequently used in studies, no normative data that are standardized in Bosnia and Herzegovina are available. Thus, we provided descriptive data for these tests that can serve as preliminary normative data for these age/ grade groups.

\section{1) Semantic Fluency}

Numerous studies examining language and relationship between language and executive functions have used semantic fluency as an 
independent variable. In this study we used a semantic category of animals. We used a standard procedure for conducting this test (Troyer, Moskovitch, \& Winocur, 1997). Children were asked to name as many animals as possible in 60 seconds. Total number of named, non-repeated, animals was used as a predictor variable.

\section{2) Phonological Fluency}

Another test of verbal fluency we used in this study was phonological fluency. The procedure is the same as for the semantic fluency task (Troyer et al., 1997). Children were asked to name as many words as possible in 60 s starting with a letter M. Number of named, non-repeated, words was used as a predictor variable.

\section{3) Rapid Object Naming test}

In this test children are required to quickly name aloud all the objects on an A4 format sheet. We adopted an object naming test because object names are the least automatized category, regardless of being acquired earlier than colors, numbers, and letters (Denckla \& Rudel, 1974). In this test we had a total of 36 pictures (12 familiar objects, each repeated 3 times) on the sheet. The time to name all the pictures was used as an outcome variable.

\section{4) Inhibitory Control - Commission Errors}

The task used for the assessment of Inhibitory Control was a computerized MultipleChoice Reaction Time Test (Di Nuovo, 2000). In this test, children are required to press the space key on a computer every time they see a star appearing on the screen and to inhibit the response when they see any other object appearing on the screen (go-no/go paradigm). The total number of stimuli presented was 45 , out of which 9 were targets. The stimuli were presented randomly. The computer program used for this assessment was Attenzione e conzentrazione (Di Nuovo, 2000), which was used previously for measuring inhibitory control in preschool chil- dren (Memisevic \& Biscevic, 2018). There are four outcome measures on this test: number of correct answers, mean reaction time, errors of omission and errors of commission. For the purposes of this study we only present the number of commission errors committed as they are a measure of inhibitory control. The other three measures are regarded as the measures of attentional control and were not used in this study.

\section{5) Selective Attention - Cancellation Test}

Selective attention was measured through a cancellation test. Cancellation tests are widely used to assess selective attention and visual search abilities. They are commonly used to asses a person's ability to simultaneously target stimuli while ignoring distracters and these tests are tapping a wide array of executive function skills such as planning, organizing information, and ignoring irrelevant information $(\mathrm{Wu}$ et al., 2017). We used a computerized Cancellation task from the program Attenzione $e$ conzentrazione (Di Nuovo, 2000). In this task children were asked to cancel out all the stars that appear on the screen. Success on the task is measured through several indices: number of omissions, number of correct answers, and completion time. However, as a predictor variable for this task we used a so-called Performance Quotient (PQ) (Huang \& Wang, 2009). $\mathrm{PQ}$ is a more precise indicator in cancellation tasks since the number of correct answers is usually not a sensitive measure due to the ceiling effect and completion time may have a wide range of scores. PQ accounts for both speed and accuracy of the performance and was calculated through this math expression:

$$
\mathrm{PQ}=\frac{\text { correct responses }}{\text { total target }} \times \frac{\text { correct responses }}{\text { completion time }}
$$

\section{6) Visual Motor Integration}

Visual motor integration, defined as the coordination of fine motor skills and perceptual abili- 
ties, is a very good indicator of a child's level of functioning and academic performance (Memisevic \& Djordjevic, 2018). In this study we used a Grooved Pegboard Test, the test that is frequently used in neuropsychological assessment batteries (Bryden \& Roy, 2005). In this test children are required to insert 25 keys into holes. Time to finish the task was used as a predictor variable.

\section{Procedure}

In this study we employed a transversal research approach. We selected two elementary schools in Canton Sarajevo and provided teachers with the consent forms for the children's parents. After the consent forms were returned, we tested the children using the tests described above. We tested a total of 210 children ( 70 children were attending first grades, 70 children were attending second grades and 70 children were attending third grades). However, for this study we only reported results for children attending second and third grades because the first graders were not administered the reading fluency test. All children were tested individually, in the morning hours, in the classrooms that were available for the testing. The order of testing was the same for all children. The approval for this study was obtained from the Canton Sarajevo Ministry of Education and the Ethical Committee Board at the Faculty of Educational
Sciences at the University of Sarajevo. Only children with written parental consent were tested.

\section{Statistical Analysis}

Descriptive results (means and standard deviations) are presented for second and third grade students of both boys and girls. To answer the first research question we performed a $t$-test and two-way ANOVA. For the second and third research questions, we performed a stepwise multiple regression. An alpha level of .05 was used for all statistical tests.

\section{Results}

We first present descriptive data (means and standard deviations) for the predictor variables of reading fluency (Table 1). As there are no normative data available for Bosnian speaking children, these data can serve as normative for future studies on this topic.

The first research aim in this study was to examine whether there are differences in reading skills in relation to gender and grade of the students. We performed a two-way analysis of variance to examine if these differences were statistically significant in relation to the gender and grade of the students, and if there exists an interaction effect of gender and grade on reading skills. Summary of these results is presented in Table 2.

Table 1 Descriptive data for the predictors of reading fluency

\begin{tabular}{lrrrr}
\hline \multirow{2}{*}{ Predictor variables } & \multicolumn{2}{c}{ Second grade } & \multicolumn{2}{c}{ Third grade } \\
& $M$ & $S D$ & $M$ & $S D$ \\
\hline Semantic fluency & 12.1 & 4.2 & 13.1 & 4.5 \\
Phonological fluency & 6.0 & 2.4 & 6.7 & 2.9 \\
Rapid naming & 54.7 & 16.1 & 51.9 & 19.4 \\
Inhibitory control & 1.1 & 1.3 & 1.0 & 1.2 \\
Visual motor integration & 97.2 & 23.9 & 86.0 & 25.9 \\
Selective attention & 23.3 & 7.3 & 27.1 & 6.8 \\
\hline
\end{tabular}


Table 2 Means, standard deviations, and analysis of variance (ANOVA) results for reading skills for gender and grade

\begin{tabular}{cccccccc}
\hline & \multicolumn{3}{c}{ Second grade } & \multicolumn{2}{c}{ Third grade } & \multicolumn{3}{c}{ ANOVA } \\
& $M$ & $S D$ & $M$ & $S D$ & Gender (Ge) & Grade $(\mathrm{Gr})$ & Ge x Gr \\
\hline Gender & & & & & $6.7^{\mathrm{a}}$ & $40.2^{\mathrm{b}}$ & $0.65^{\mathrm{c}}$ \\
Boys & 59.3 & 31.2 & 90.4 & 35.0 & & & \\
Girls & 69.3 & 34.3 & 109.5 & 32.1 & & & \\
\hline Note. ${ }^{\mathrm{a}} \mathrm{p}=.011, \dot{\eta}^{2}=.05 ;{ }^{\mathrm{b}} \mathrm{p}=.001, \dot{\eta}^{2}=.23 ;{ }^{\mathrm{c}} \mathrm{p}=.42, \dot{\eta}^{2}=.005$. &
\end{tabular}

As can be seen from Table 2, girls outperformed boys on the task of reading fluency in both, second grade and third grade. However, according to the results of an independent $t$-test, these differences were statistically significant for the third grade students, but not for the second grade students (third grade: $t(68)=$ $2.4 ; p=.021$; second grade: $t(68)=1.3 ; p=.21)$. As can be seen from the table, there was an increase for both, boys and girls in reading fluency from second grade to third grade. For the boys the overall improvement in reading fluency from second grade to the third grade was $52.4 \%$, and for the girls the improvement from second to third grade was $58 \%$. However, as this is a cross-sectional study, this improvement in percentage $(\%)$ should serve only as an indicator, as there are no national norms for reading fluency.

Results of ANOVA clearly show that there are statistically significant gender and grade effects, and there is a lack of their interaction effect on reading skills. Girls read more fluently than boys in both, second and third grade, and as expected, reading fluency improved significantly from second grade to third grade.

We next performed a correlation between all the measures in the study. These results are shown in Table 3.

As can be seen from Table 3, reading skills are significantly correlated with all the predictors. Also, as can be seen from Table 3, the issue of multicollinearity was not problematic, since the predictors were not highly correlated among each other. Thus, we next performed a stepwise multiple regression with all the predictors. The results have shown that the significant predictors of reading skills were semantic fluency, rapid naming, inhibitory control, and selective attention. Visual-motor integration $(t=0.6 ; p=.58)$ along with phonological fluency $(t=1.86 ; p=.064)$ were not significant

Table 3 Correlation between reading skills and the predictors

\begin{tabular}{lccccccc}
\hline & READ & SF & PF & RN & INH_CON & VMI & SA \\
\hline READ & 1.00 & $.31^{* *}$ & $.31^{* *}$ & $-.29^{* *}$ & $-.18^{*}$ & $-.17^{*}$ & $.31^{* *}$ \\
SF & - & 1.00 & $.47^{* *}$ & $-.30^{* *}$ & -.04 & $-.17^{*}$ & .10 \\
PF & - & - & 1.00 & $-.22^{* *}$ & -.02 & $-.26^{* *}$ & .14 \\
RN & - & - & - & 1.00 & $.03^{*}$ & $.19^{*}$ & $-.17^{*}$ \\
INH_CON & - & - & - & - & 1.00 & $.25^{* *}$ & .06 \\
VMI & - & - & - & - & - & 1.00 & $-.34^{* *}$ \\
SA & - & - & - & - & - & - & 1.00 \\
\hline
\end{tabular}

Note. READ - reading skills; SF - semantic fluency; PF - phonological fluency; RN - rapid naming; INH_CON - inhibitory control; VMI - visual motor integration skills; SA - selective attention.

$* \mathrm{p}<.05 ; * * \mathrm{p}<.01$. 
predictors of reading fluency. In Table 4 are the results of a stepwise multiple regression, with all statistically significant predictors.

The model presented in Table 4 was statistically significant $F(4)=10.5 ; p<.001$, although it only explained around $24 \%$ of the scores in reading fluency. The strongest predictor of reading ability was Selective Attention, followed by Semantic Fluency, Inhibitory Control and Rapid Naming. In order to obtain better insight into these results we also wanted to check whether these predictors are the same and have the same strength for both second grade students and third grade students. The results of multiple regression are shown in Table 5.

As can be seen from Table 5, the prediction model changes if the sample is split between second grade and third grade students. For second grade students, the model changed drastically and the only significant predictor of reading fluency was rapid naming, which explained around $15 \%$ of variance in scores on reading fluency. For the third grade students, the model did not change significantly. The only difference from the original model was that the variable rapid naming did not reach statistical significance. However, for third graders the model explained almost $1 / 3$ of the variance on the scores in reading fluency. It is evident that the initial model was more applicable to third grade students and better predicted their scores.

\section{Discussion}

The goal of this study was to examine the gender effects on reading and factors contributing to reading fluency in children attending second and third grades of elementary school. Our first research question dealt with gender differences in reading fluency. The results of this study showed that girls outperformed boys in both second and third grades, but statisti-

Table 4 A stepwise multiple regression for predicting reading fluency

\begin{tabular}{lrrrrc}
\hline Predictors & $B$ & $S E B$ & $\beta$ & $t$ & $p$ \\
\hline SA & 1.42 & .40 & .27 & 3.55 & .001 \\
SF & 1.96 & .68 & .23 & 2.86 & .005 \\
INH_CON & -5.32 & 2.20 & -.18 & -2.42 & .017 \\
RN & -0.37 & 0.17 & -.17 & -2.16 & .032 \\
\hline Note. $\mathrm{R}^{2}=.24$ (unadjusted), $\mathrm{R}^{2}=.22$ (adjusted). SA - selective attention; SF - semantic
\end{tabular}

fluency; INH_CON - inhibitory control; $\mathrm{RN}$ - rapid naming.

Table 5 A stepwise multiple regression for predicting reading fluency for second and third grade students

\begin{tabular}{lrrrrrr}
\hline Predictors & & $B$ & $S E B$ & $\beta$ & $t$ & $p$ \\
\hline $2^{\text {nd }}$ Grade $^{\mathrm{a}}$ & & & & & & \\
& Rapid naming & -.81 & .23 & -.40 & -3.60 & $<.01$ \\
\hline $3^{\text {rd }}$ Grade $^{\mathrm{b}}$ & & & & & & \\
& SA & 1.22 & .53 & .24 & 2.31 & .024 \\
& SF & 2.87 & .80 & .37 & 3.58 & $<.01$ \\
& INH_CON & -6.96 & 2.90 & -.25 & -2.41 & .019 \\
\hline
\end{tabular}

Note. ${ }^{\mathrm{a}} \mathrm{R}^{2}=.16$ (unadjusted); $\mathrm{R}^{2}=.14$ (adjusted); ${ }^{\mathrm{b}} \mathrm{R}^{2}=.30$ (unadjusted); $\mathrm{R}^{2}=.27$ (adjusted). SA - selective attention; SF - semantic fluency; INH_CON - inhibitory control. 
cally significant differences were only found for third graders. The results of previous studies on gender differences in reading have found mixed results. A large meta-analysis conducted by Hyde and Linn (1988) showed that gender differences for most types of verbal abilities are negligible across development, except for speech production which favors females. A study by Klein and Jimerson (2005) examined gender differences in reading fluency in children grades 1-3 and found no differences between boys and girls. However, it seems that some differences in reading ability appear later in development. For example, Berninger et al. (2008) found that men had more difficulties than women in reading abilities, but no such differences were found between boys and girls.

One possible explanation for gender differences in this study might lie in motivational and attitudinal factors in reading. It has been shown that girls have more positive attitudes towards reading than boys (Logan \& Johnston, 2009) and perhaps the difference stemmed from higher interest of girls towards reading materials. Thus, motivational factors such as attitudes and interests should be controlled in future studies.

As for the predictors of reading fluency, the results of this study have indicated that rapid object naming, selective attention, inhibitory control and semantic fluency are significantly associated with reading fluency. However, the significant predictors were not the same for students in second and third grades. For the second grade students the only significant predictor of reading fluency was rapid naming, while for the third graders the significant predictors were semantic fluency, inhibitory control, and selective attention.

Rapid naming is a very good predictor of reading skills in early school grades (Manis, Seidenberg, \& Doi, 2009). It is also one of the most widely studied predictors of reading fluency. In this study, rapid naming had a larger effect on reading fluency in second than in third grade students. There are several potential explanations for this result. Rapid naming is a test of processing information. It might be the case that these results are dependent on the naming category. In the present study, we used pictures of familiar objects and animals to be named. We might have achieved different results if we had used alphanumeric naming tasks, which are known to better differentiate impaired readers (Wolf, 1991). It might be the case that naming of familiar objects becomes more automatic with age, so the differences among children and their effect on reading is reduced. This explanation is in line with a hypothesis that naming speed is a lower level process, which is a major factor in initial stages of reading and disappears in later grades (Walsh, Price, \& Gillingham, 1988).

In this study, selective attention had the largest effect on reading fluency. Previous studies have shown that deficits in selective attention have negative effects on reading efficiency (Casco, Tressoldi, \& Dellantonio, 1998). But the question remains on why was selective attention the most significant predictor of reading fluency for third grade students but not for second grade students? The answer to this question might be related to earlier theories of reading, where selective attention played a central role (Willows, 1974). In line with that theory, the probable explanation is that older children attend more successfully to the more important words, ignore those that are redundant and can connect the text logically. Selective attention is a complex ability, which incorporates the competency of focusing on target stimuli as well as the inhibition of unimportant stimuli. It is important to note that we used a Performance Quotient on the cancellation task as a measure of selective attention. This measure takes into account both speed and accuracy of the performance and this measure can probably better predict reading success and should thus be used more widely as a predictor of reading fluency. Also of note is that PQ is not a pure mea- 
sure of selective attention as it taps other skills as well, such as visuospatial function. Future studies should examine the other measures of selective attention as well.

The second strongest predictor of reading fluency for third graders was semantic fluency. Interestingly, there is a lack of research examining the link between semantic fluency and reading fluency. There are, however, many studies in which semantic fluency was correlated with other constructs important for reading such as working memory and executive functions (Biscevic, Pasalic, \& Memisevic, 2018; Daneman, 1991). One possible explanation of why semantic fluency was a significant predictor might be the fact that semantic fluency has a linear trajectory line until the age of 10 , and as the children age, there is higher variance in the scores. Thus, the fluency scores of third graders might have been influenced more by semantic fluency than the scores of second graders.

The last significant predictor in our model was inhibitory control. It is a well-established fact that older children have better inhibitory control than younger children. However, the exact nature of the relationship between inhibitory control and reading is not clear. It is well established that reading involves both automatic and control processes. Inhibitory control can be viewed as a control process involving allocation of attention and working memory to reading (Walczik, 2000). Thus, the older childen, were able to better use these resources in decoding unfamiliar words and resolving any inconsistencies in the text because the process of decoding is more automatized. Studies to date have shown that poor readers have difficulties in inhibitory control (Chiappe et al., 2000).

Children differ widely in their prerequisite skills when entering primary schools. The role of educators, both preschool and elementary school teachers, is to reduce these gaps in skills. Much has been written about the socalled Matthew effects in reading, defined as a widening achievement gap between good and poor readers, and although the topic is inconclusive (Pfost, Hattie, Dorfler, \& Artelt, 2014), the teachers need to be aware of this phenomena and start using reading interventions as soon as possible. Reading difficulties tend to be stable across school age. Around $70 \%$ of children who were poor readers at Grade 1, continue to be poor readers at Grade 8 (Landerl \& Wimmer, 2008). Teacher education programs should thus incorporate discussions on different teaching methods proven to improve reading (Kikas et al., 2017). This study is important as it can point the researchers and practitioners to the strategies that can be used to enhance academic achievements in reading. According to developmental theories, reading development is cumulative in the sense that later skills are built on foundational skills (Kieffer, 2011). Therefore, it is important to identify the skills that constitute the foundation of reading. The results of this study can offer some useful guidelines. In particular, this study points to the importance of selective attention in reading fluency. Instructions aimed at practicing selective attention can probably have a positive impact on reading. In addition to improving selective attention, practice in verbal fluency and inhibitory control can also serve the function of improving reading fluency in children (KolićVehovec, 2002). Educators can use a number of strategies to improve these skills in children. Short, high-intensity physical activities have been shown to improve selective attention in school children (Ma, Le Mare, \& Gurd, 2014). Some preschool programs such as Tools of Mind can help to improve inhibitory control in preschool children (Diamond, Barnett, Thomas, \& Munro, 2007). Educators need to share information with parents on effective strategies for increasing reading skills. This is because within family factors, such as home literacy environment, have a large effect on child's literacy (Puglisi et al., 2017). 
Our study is the first one examining the predictors of reading fluency in Bosnian language. As there might be different effects of various predictors on reading fluency, depending on the orthographic complexities, this study is warranted. Most of the studies on predictors of reading have been conducted in English speaking countries, thus it is important to determine these predictors for languages with transparent orthographies. Bosnian language has a socalled shallow or transparent orthography, meaning that the connections between the letters and speech sounds are consistent. It is a well-established fact that learning to read is easier in languages that have consistent grapheme-phoneme correspondence (transparent orthographies) than in languages that have inconsistencies (Solheim, Frijters, Lundetrae, \& Uppstad, 2018). We believe that the results of this study could be transferable to similar languages as well, especially to the Serbian and Croatian language, as they are very similar to Bosnian and also have transparent orthography.

There are a couple of limitations of this study that need to be mentioned. First, the design of this study was cross-sectional, so we need to be cautious in concluding that there is a real change in the predictors of reading fluency. The difference in the predictors might have been sample specific. This calls for future longitudinal studies which will provide us with more precise answer to this question. Second, although the sample size was sufficient for the overall research question, the sample for subgroups analysis (grades) was barely enough - thus future studies need to include more participants. Finally, we did not include some other predictors that proved significant in earlier studies such as IQ, phonological awareness and working memory, which might share the same variance in explaining reading fluency. Future studies would benefit from including all these significant predictors and testing them together in order to create even better models for prediction of reading fluency.

\section{Conclusion}

Knowing the predictors of reading fluency will help educators create better programs for enhancing reading skills of all learners. This study has pointed to four predictors of reading fluency: selective attention, semantic fluency, inhibitory control, and rapid naming. All these skills are susceptible to training and should thus be the focus of early intervention in preschool years.

\section{References}

Allan, N. P., Hume, L. E., Allan, D. M., Farrington, A. L., \& Lonigan, C. J. (2014). Relations between inhibitory control and the development of academic skills in preschool and kindergarten: A metaanalysis. Developmental Psychology, 50(10), 23682379. doi: 10.1037/a0037493

Altemeier, L. E., Abbott, R. D., \& Berninger, V. W. (2008). Executive functions for reading and writing in typical literacy development and dyslexia. Journal of Clinical and Experimental Neuropsychology, 30(5), 588-606. doi: 10.1080/ 13803390701562818

Anthony, J. L., \& Francis, D. J. (2005). Development of phonological awareness. Current Directions in Psychological Science, 14(5), 255-259. doi: 10.1111/j.0963-7214.2005.00376.x

Antonacci, P. A., O’Callaghan, C. M., \& Berkowitz, E. (2014). Developing content area literacy: 40 strategies for middle and secondary classrooms. Sage Publications

Bashir, A. S., \& Hook, P. E. (2009). Fluency: A key link between word identification and comprehension. Language, Speech, and Hearing Services in Schools, 40(2), 196-200. doi: 10.1044/01611461(2008/08-0074)

Berninger, V. W., Nielsen, K. H., Abbott, R. D., Wijsman, E., \& Raskind, W. (2008). Gender differences in severity of writing and reading disabilities. Journal of School Psychology, 46(2), 151-172. doi: 10. 1016/j.jsp.2007.02.007

Biscevic, I., Pasalic, A., \& Memisevic, H. (2018). The effects of executive functions and theory of mind on semantic fluency in preschool children. Problems of Education in the 21st Century, 76(1), 21-28. 
Bryden, P. J., \& Roy, E. A. (2005). A new method of administering the Grooved Pegboard Test: Performance as a function of handedness and sex. Brain and Cognition, 58(3), 258-268. doi: $10.1016 / \mathrm{j}$. bandc. 2004.12 .004

Bus, A. G., \& Van IJzendoorn, M. H. (1999). Phonological awareness and early reading: A meta-analysis of experimental training studies. Journal of Educational Psychology, 91(3), 403. doi: 10.1037/00220663.91 .3 .403

Carrillo, M. (1994). Development of phonological awareness and reading acquisition. Reading and Writing, 6(3), 279-298. doi: 10.1007/BF01027086

Casco, C., Tressoldi, P. E., \& Dellantonio, A. (1998). Visual selective attention and reading efficiency are related in children. Cortex, 34(4), 531-546. doi: 10.1016/S0010-9452(08)70512-4

Chiappe, P., \& Siegel, L. S. (1999). Phonological awareness and reading acquisition in English- and Punjabispeaking Canadian children. Journal of Educational Psychology, 91(1), 20-28. doi: 10.1037/00220663.91 .1 .20

Chiappe, P., Siegel, L. S., \& Hasher, L. (2000). Working memory, inhibitory control, and reading disability. Memory \& Cognition, 28(1), 8-17. doi: 10.3758/BF03211570

Clinton, V., Seipel, B., van den Broek, P., McMaster, K. L., Kendeou, P., Carlson, S. E., \& Rapp, D. N. (2014). Gender differences in inference generation by fourth-grade students. Journal of Research in Reading, 37(4), 356-374. doi: 10.1111/j.14679817.2012.01531.x

Cohen-Mimran, R. (2009). The contribution of language skills to reading fluency: A comparison of two orthographies for Hebrew. Journal of Child Language, 36(3), 657-672. doi: 10.1017/ S0305000908009148

Colé, P., Duncan, L. G., \& Blaye, A. (2014). Cognitive flexibility predicts early reading skills. Frontiers in Psychology, 5(565), 1-8. doi: 10.3389/fpsyg.2014. 00565

Cunningham, A. E., \& Stanovich, K. E. (1997). Early reading acquisition and its relation to reading experience and ability 10 years later. Developmental Psychology, 33(6), 934-945. doi: 10.1037/0012-1649. 33.6.934

Daneman, M. (1991). Working memory as a predictor of verbal fluency. Journal of Psycholinguistic Research, 20(6), 445-464. doi: 10.1007/ BF0 1067637

David, D., Wade-Woolley, L., Kirby, J. R., \& Smithrim, K. (2007). Rhythm and reading development in school-age children: A longitudinal study. Journal of Research in Reading, 30(2), 169-183. doi:10.1111/ j.1467-9817.2006.00323.x
Denckla, M. B., \& Rudel, R. (1974). Rapid "automatized" naming of pictured objects, colors, letters and numbers by normal children. Cortex, 10(2), 186-202. doi: 10.1016/S0010-9452(74)80009-2

Deno, S. L. (1985). Curriculum-based measurement:The emerging alternative. Exceptional Children, 52(3), 219-232. doi: 10.1177/001440298505200303

Diamond, A., Barnett, W. S., Thomas, J., \& Munro, S. (2007). Preschool program improves cognitive control. Science (New York, NY), 318(5855), 13871388. doi: $10.1126 /$ science. 1151148

Di Nuovo, S. (2000). Attenzione e concentrazione. Trento, Italy: Edizioni Centro Studi Erickson.

Francis, D. J., Shaywitz, S. E., Stuebing, K. K., Shaywitz, B. A., \& Fletcher, J. M. (1996). Developmental lag versus deficit models of reading disability: A longitudinal, individual growth curves analysis. Journal of Educational Psychology, 88(1), 3-17. doi: 10.1037/ 0022-0663.88.1.3

Fuchs, L. S., Fuchs, D., Hosp, M. K., \& Jenkins, J. R. (2001). Oral reading fluency as an indicator of reading competence: A theoretical, empirical, and historical analysis. Scientific Studies of Reading, 5(3), 239-256. doi: 10.1207/S1532799XSSR0503_3

Guo, Y., Sun, S., Breit-Smith, A., Morrison, F. J., \& Connor, C. M. (2015). Behavioral engagement and reading achievement in elementary-school-age children: A longitudinal cross-lagged analysis. Journal of Educational Psychology, 107(2), 332-347. doi: $10.1037 / \mathrm{a} 0037638$

Hasbrouck, J., \& Tindal, G. A. (2006). Oral reading fluency norms: A valuable assessment tool for reading teachers. The Reading Teacher, 59(7), 636-644. doi: 10.1598/RT.59.7.3

Hoover, W. A., \& Gough, P. B. (1990). The simple view of reading. Reading and Writing, 2(2), 127160. doi: 10.1007/BF00401799

Huang, H. C., \& Wang, T. Y. (2009). Stimulus effects on cancellation task performance in children with and without dyslexia. Behavior Research Methods, 41(2), 539-545. doi: 10.3758/BRM.41. 2.539

Hyde, J. S., \& Linn, M. C. (1988). Gender differences in verbal ability: A meta-analysis. Psychological Bulletin, 104(1), 53-69. doi:10.1037/0033-2909. 104.1.53

Katzir, T., Kim, Y., Wolf, M., O’Brien, B., Kennedy, B., Lovett, M., \& Morris, R. (2006). Reading fluency: The whole is more than the parts. Annals of Dyslexia, 56(1), 51-82. doi: 10.1007/s11881-0060003-5

Kikas, E., Pakarinen, E., Soodla, P., Peets, K., \& Lerkkanen, M. K. (2017). Associations between reading skills, interest in reading, and teaching practices in first grade. Scandinavian Journal of Educational 
Research, 62(6), 1-18. doi: 10.1080/00313831. 2017.1307272

Kirby, J. R., Parrila, R. K., \& Pfeiffer, S. L. (2003). Naming speed and phonological awareness as predictors of reading development. Journal of Educational Psychology, 95(3), 453-464. doi: 10.1037/ 0022-0663.95.3.453

Kieffer, M. J. (2011). Converging trajectories: Reading growth in language minority learners and their classmates, kindergarten to grade 8. American Educational Research Journal, 48(5), 1187-1225.doi: $10.3102 / 0002831211419490$

Klein, J. R., \& Jimerson, S. R. (2005). Examining ethnic, gender, language, and socioeconomic bias in oral reading fluency scores among Caucasian and Hispanic students. School Psychology Quarterly, 20(1), 23-50.doi: 10.1521/scpq.20.1.23.64196

Kolić-Vehovec, S. (2002). Effects of self-monitoring training on reading accuracy and fluency of poor readers. European Journal of Psychology of Education, 17(2), 129-138. doi: 10.1007/BF03173254

Landerl, K., \&Wimmer, H. (2008). Development of word reading fluency and spelling in a consistent orthography: An 8-year follow-up. Journal of Educational Psychology,100(1), 150-161. doi: 10.1037/0022-0663.100.1.150

Levy, B. (2001). Moving the bottom: Improving reading fluency. In M. Wolf (Ed.), Dyslexia, fluency, and the brain (pp. 357-379). Timonium, MD: York Press.

Logan, S., \& Johnston, R. (2009). Gender differences in reading ability and attitudes: Examining where these differences lie. Journal of Research in Reading, 32(2), 199-214. doi:10.1111/j.1467-9817. 2008.01389.x

Lonigan, C. J., Burgess, S. R., \& Anthony, J. L. (2000). Development of emergent literacy and early reading skills in preschool children: Evidence from a latent-variable longitudinal study. Developmental Psychology, 36(5), 596-613. doi: 10.1037/00121649.36.5.596

Ma, J. K., Le Mare, L., \& Gurd, B. J. (2014). Four minutes of in-class high-intensity interval activity improves selective attention in 9- to 11-year olds. Applied Physiology, Nutrition, and Metabolism, 40(3), 238-244. doi: 10.1139/apnm-20140309

Manis, F. R., Seidenberg, M. S., \& Doi, L. M. (1999). See Dick RAN: Rapid naming and the longitudinal prediction of reading subskills in first and second graders. Scientific Studies of Reading, 3(2), 129-157. doi: $10.1207 / \mathrm{s} 1532799 \times$ ssr0302_3

Memisevic, H., \& Biscevic, I. (2018). Exploring the link between inhibitory control and cognitive flexibility in preschool children. Cognition, Brain,
Behavior, 22(1), 1-11. doi: 10.24193/cbb.2018. 22.01

Memisevic, H., \& Djordjevic, M. (2018). Visual-motor integration in children with mild intellectual disability: A meta-analysis. Perceptual and Motor Skills, 125(4), 696-717. doi: 10.1177/0031512518774137 Monette, S., Bigras, M., \& Guay, M. C. (2011). The role of the executive functions in school achievement at the end of Grade 1. Journal of Experimental Child Psychology, 109(2), 158-173. doi: 10.1016/j.jecp.2011.01.008

Morris, D., \& Perney, J. (2018). Using a sight word measure to predict reading fluency problems in grades 1 to 3. Reading \& Writing Quarterly, 34(4), 338348. doi: 10.1080/10573569.2018.1446857

Netten, A., Droop, M., \& Verhoeven, L. (2011). Predictors of reading literacy for first and second language learners. Reading and Writing, 24(4), 413425. doi: 10.1007/s11145-010-9234-2

Norton, E. S., \& Wolf, M. (2012). Rapid automatized naming (RAN) and reading fluency: Implications for understanding and treatment of reading disabilities. Annual Review of Psychology, 63, 427-452. doi: 10.1146/annurev-psych-120710-100431

Öney, B., \& Durgunoğlu, A. Y. (1997). Beginning to read in Turkish: A phonologically transparent orthography. Applied Psycholinguistics, 18(1), 1-15. doi: $10.1017 / \mathrm{S} 014271640000984 \mathrm{X}$

Paris, S. G. (2005). Reinterpreting the development of reading skills. Reading Research Quarterly, 40(2), 184-202. doi: 10.1598/RRQ.40.2.3

Pfost, M., Hattie, J., Dörfler, T., \& Artelt, C. (2014). Individual differences in reading development: $\mathrm{A}$ review of 25 years of empirical research on Matthew effects in reading. Review of Educational Research, 84(2), 203-244. doi: 10.3102/ 0034654313509492

Puglisi, M. L., Hulme, C., Hamilton, L. G., \& Snowling M. J. (2017). The home literacy environment is a correlate, but perhaps not a cause, of variations in children's language and literacy development. Scientific Studies of Reading, 21(6), 498-514. doi: 10.1080/10888438.2017.1346660

Puolakanaho, A., Ahonen, T., Aro, M., Eklund, K., Leppänen, P. H., Poikkeus, A. M., ... \& Lyytinen, H. (2008). Developmental links of very early phonological and language skills to second grade reading outcomes: Strong to accuracy but only minor to fluency. Journal of Learning Disabilities, 41(4), 353-370. doi: 10.1177/0022219407311747

Reiter, A., Tucha, O., \& Lange, K. W. (2005). Executive functions in children with dyslexia. Dyslexia, 11(2), 116-131. doi: 10.1002/dys.289

Solheim, O. J., Frijters, J. C., Lundetræ, K., \& Uppstad, P. H. (2018). Effectiveness of an early reading in- 
tervention in a semi-transparent orthography: A group randomised controlled trial. Learning and Instruction, 58, 65-79. doi: 10.1016/j.learninstruc. 2018.05.004

Stahl, S. A., \& Murray, B. A. (1994). Defining phonological awareness and its relationship to early reading. Journal of Educational Psychology, 86(2), 221-234. doi: 10.1037/0022-0663.86.2.221

Teale, W. H., Whittingham, C. E., \& Hoffman, E. B. (2018). Early literacy research, 2006-2015: A decade of measured progress. Journal of Early Childhood Literacy, 0(0), 1-54. doi: 10.1177/ 1468798418754939

Torgesen, J. K., \& Hudson, R. F. (2006). Reading fluency: Critical issues for struggling readers. In S. J. Samuels \& A. Farstrup (Eds.). What research has to say about fluency instruction (pp. 130-158). Newark, DE: International Reading Association.

Troyer, A. K., Moscovitch, M., \& Winocur, G. (1997). Clustering and switching as two components of verbal fluency: Evidence from younger and older healthy adults. Neuropsychology, 11(1), 138-146. doi: 10.1037/0894-4105.11.1.138

Voyer, D., \& Voyer, S. D. (2014). Gender differences in scholastic achievement: A meta-analysis. Psychological Bulletin, 140(4), 1-31. doi: 10.1037/ a0036620
Wagner, D. A. (2017). Children's reading in low-income countries. The Reading Teacher, 71(2), 127133. doi: $10.1002 / \operatorname{trtr} .1621$

Walczyk, J. J. (2000). The interplay between automatic and control processes in reading. Reading Research Quarterly, 35(4), 554-566. doi: 10.1598/ RRQ.35.4.7

Walsh, D. J., Price, G. G., \& Gillingham, M. G. (1988). The critical but transitory importance of letter naming. Reading Research Quarterly, 23(1), 108122. doi: $10.2307 / 747907$

Willows, D. M. (1974). Reading between the lines: Selective attention in good and poor readers. Child Development, 45(2), 408-415. doi: 10.2307/ 1127962

Wolf, M. (1991). Naming speed and reading: The contribution of the cognitive neurosciences. Reading Research Quarterly, 26(2), 123-141. doi: 10.2307/ 747978

Wolf, M., \& Katzir-Cohen, T. (2001). Reading fluency and its intervention. Scientific Studies of Reading, 5(3), 211-239. doi: 10.1207/S1532799XSSR0503_2

Wu, Y. H., Vidal, J. S., de Rotrou, J., Sikkes, S. A., Rigaud, A. S., \& Plichart, M. (2017). Can a tabletbased cancellation test identify cognitive impairment in older adults?. PloS one, 12(7), 1-14. doi: 10.1371/journal.pone.0181809 